\title{
Growth Inhibition of Film-Forming Yeasts During Production of Ume-Zuke (Pickled Japanese Apricots) by an Antimicrobial Fraction Extracted from Paprika Seeds
}

\author{
Mizuo Yajima, ${ }^{1}$ Kazuhiko Nozaki, ${ }^{1}$ Tsutomu TakayanagI,${ }^{2}$ Chikao Otoguro ${ }^{3}$ and Koki Yokotsuka ${ }^{2}$ \\ ${ }^{1}$ Asama Chemical Co., Ltd., 20-3, Nihonbashi-Kodenma-cho, Chuo-ku, Tokyo 103-0001, Japan \\ ${ }^{2}$ The Institute of Enology and Viticulture, Yamanashi University, Kofu, Yamanashi 400-0005, Japan \\ ${ }^{3}$ Bio-technology Section, The Yamanashi Industrial Technology Center, 2094, Otsu-cho, Kofu, Yamanashi 400-0055, Japan
}

Received August 19, 1997; Accepted April 23, 1998

\begin{abstract}
Paprika extract (50 to $100 \mu \mathrm{g} / \mathrm{ml}$ ) obtained by suspending ground paprika seeds in water, adding ethanol (50\%, v/v), and then filtering the suspension, inhibited the growth of film-forming yeasts (Kloeckera, Pichia, Debaryomyces, and Candida species) isolated during the production of ume-zuke, a processed food product made by salting Japanese apricots (Prunus mume). The antimicrobial activity of the extract towards Pichia anomala was influenced by the initial number of yeast cells, as well as the temperature, $\mathrm{pH}$, and sodium chloride concentration of the culture medium (ume vinegar). The inhibitory effect was cumulatively enhanced, although not synergistically, when the paprika seed extract was used in combination with either $\mathrm{SO}_{2}$, sorbic acid, thiamine dilauryl sulfate, or acetic acid. The antimicrobial activity of the extract was not influenced by the vinegar components. The extract proved to be very effective as a preservative to prevent the contamination and spoilage of ume-zuke by film-forming yeasts.
\end{abstract}

Keywords: antimicrobial substances, paprika seed, film-forming yeast, ume-zuke

Until recently, the possibility of microbial contamination in the production of ume-zuke, a processed ume (Japanese apricot) product, has not been considered because it has traditionally been produced and preserved using a high concentration of salt and in the presence of organic acids which give the product a low $\mathrm{pH}$. However, due to health considerations, an increasing number of people prefer umezuke with a lower salt concentration, which increases the risk of microbial contamination and spoilage mainly due to the presence of film-forming yeasts. During the production of ume-zuke, acid-resistant and/or salt-resistant film-forming yeasts occur during the salt preservation stage (i.e., the primary processing stage) (Onda et al., 1997a), and develop as colonies on the fruit surface at or after desalinization and seasoning (the secondary processing stage). Therefore, a natural preservative with high antimicrobial activity against film-forming yeasts is essential.

Yajima et al. $(1996,1997)$ reported that the precipitate fractionated from an aqueous water-extract of paprika seeds by salting out with ammonium sulfate demonstrated antimicrobial activity against several yeasts. This precipitate was partially purified by performing successive column chromatography steps. The present study describes the utilization of a paprika seed extract to inhibit the growth of film-forming yeasts isolated from ume-zuke during the primary processing stage in order to prevent its contamination and spoilage.

\section{Materials and Methods}

Preparation of antimicrobial fraction from $50 \%$ ethanol aqueous paprika seed extract Paprika seeds $(1 \mathrm{~kg})$ were ground to a powder in a mechanical grinder (Type D3V-B; Miyako Bussan Co., Ltd., Osaka). The powder was mixed with $2 l$ of water and stirred for $4 \mathrm{~h}$ at $40^{\circ} \mathrm{C}$. To this suspension, $5 l$ of $70 \%$ ethanol was added and the solution was stirred for an additional $2 \mathrm{~h}$. After suction filtering, the filtrate was concentrated to one-third its original volume by rotary evaporation at $40^{\circ} \mathrm{C}$, and then sterilized by autoclaving.

Yeasts tested Five film-forming yeast strains (Kloeckera apiculata YITC 203; Pichia anomala YITC 201, and YITC 256; Debaryomyces hansenii YITC 214; Candida guilliermondii YITC 222) were used. They were procured from ume-zuke production plants in Yamanashi prefecture, and isolated and purified at the Yamanashi Industrial Technology Center (Onda et al., 1997b).

Preparation of ume-vinegar medium One hundred kilograms of Japanese apricots (Koshu koume, Prunus mume Sieb. et. Zucc. var. microcarpa Makino) were washed with water and placed in a large vessel. After adding $20 \mathrm{~kg}$ of table salt (sodium chloride), a heavy stone was placed on the salted fruits as a weight and they were allowed to stand at room temperature for 2 weeks, which yielded $35 l$ of ume vinegar ( $\mathrm{NaCl} 17.4 \%$, total acid 4.4\%, $\mathrm{pH} 1.94)$. A mixture of ume vinegar and water $(1: 3, \mathrm{v} / \mathrm{v})$ was used as the ume vinegar culture medium.

Assays for minimum inhibitory concentration Five film-forming yeast strains ( $K$. apiculata YITC 203, $P$. anomala YITC 201 and YITC 256, C. guilliermondii YITC 222, and D. hansenii YITC 214) were pre-cultivated in YM medium containing $5 \%$ sodium chloride $\left(\mathrm{pH} 6.0\right.$ ) at $25^{\circ} \mathrm{C}$ for 2 days. The ume vinegar medium $(5 \mathrm{ml})$ was placed in a test tube $(17.5 \times 130 \mathrm{~mm})$ and the $50 \%$ ethanol extract of paprika seeds was added to yield a concentration of $6.25,12.5,25,50$, 100,200 , or $300 \mathrm{mg}$ dry weight $/ l$. The mixture was sterilized by heating at $65^{\circ} \mathrm{C}$ for $15 \mathrm{~min}$, and $50 \mu \mathrm{l}$ of the pre-cultured 
yeast $\left(10^{5}\right.$ cells $/ \mathrm{ml}$ as determined using a Thoma counting chamber) was inoculated into the mixture. The mixture was statically incubated at $25^{\circ} \mathrm{C}$ for 10 days after sealing the test tube with a silicone foam plug, and the minimum inhibitory concentration of the $50 \%$ ethanol extract of paprika seeds was determined by observing the existence and degree of film on the surface of the culture medium. The yeast cell growth was monitored by following the optical density at $660 \mathrm{~nm}$. Various other antimicrobial substances, including potassium metabisulfite ('extra pure,' Showa Chemical Co., Ltd., Tokyo), potassium sorbate ('guaranteed reagent,' Tokyo Kasei Kogyo Co., Ltd., Tokyo), acetic acid ('Japanese Industrial Standards [JIS] guaranteed reagent,' Showa Chemical Co., Ltd.), and thiamine dilauryl sulfate (Vitagen AS2, Tanabe Seiyaku Co., Ltd., Osaka), were also tested for antimicrobial activity against the film-forming yeasts. Due to their volatility, potassium metabisulfite and acetic acid were only added to the mixture after the ume vinegar medium had been sterilized by heating.

The effects of initial number of yeast cells, temperature, $\mathrm{pH}$ and $\mathrm{NaCl}$ concentration on the minimum inhibitory concentration of $50 \%$ ethanol paprika seed extract and other preservatives The effects of the culture conditions such as initial number of yeast cells, temperature, $\mathrm{pH}$ and $\mathrm{NaCl}$ concentration on the minimum inhibitory concentration of $50 \%$ ethanol paprika seed extract and other preservatives toward $P$. anomala YITC 256 were investigated. In the experiments, $P$. anomala YITC 256 cells were added to the solution to yield the final cell number of $10^{2}$ to $10^{7} / \mathrm{ml}$, the $\mathrm{pH}$ of the ume vinegar medium was adjusted from 1.5 to 4.0 , the $\mathrm{NaCl}$ concentration was increased from $4.4 \%$ for the original concentration in the ume vinegar medium to 12.4 to $22.4 \%$ by adding table salt, and the culture medium temperature was varied between $10^{\circ} \mathrm{C}$ and $35^{\circ} \mathrm{C}$. The culture medium was incubated for 10 days, and the minimum inhibitory concentration of each preservative was determined by observing the existence and extent of film on the surface of the culture medium.

Antimicrobial activity of 50\% ethanol paprika seed extract and another antimicrobial substance The antimicrobial activity of the $50 \%$ ethanol extract of paprika seeds toward the film-forming yeasts was assayed in combination with potassium metabisulfite, potassium sorbate, acetic acid, or thiamine dilauryl sulfate. The $50 \%$ ethanol extract of paprika seeds was added to yield a final concentration of 6.25 , $12.5,25,50,100$, or $200 \mathrm{mg}$ dry weight/ $l$. The four other preservatives were also added to give the various concentrations. The initial number of each of the five film-forming yeasts was $10^{5}$ cells $/ \mathrm{ml}$. The mixture was statically incubated at $25^{\circ} \mathrm{C}$ for 10 days, and its minimum inhibitory concentration was determined.

\section{Results and Discussion}

Minimum inhibitory concentration of 50\% ethanol aqueous paprika seed extract and other antimicrobial substances toward isolated film-forming yeasts In a previous study (Yajima et al., 1996), the ammonium sulfate precipitate from an aqueous paprika seed extract was investigated. In the present study, however, the antimicrobial fraction was not prepared by ammonium sulfate precipitation because this method would be impractical in commercial use due to its high production cost and low yield. Paprika seed extract obtained using only water can not be easily filtered through filter paper, which causes a considerable amount of antimicrobial activity to be lost during filtration. Therefore, ethanol was added to the aqueous extract to yield a final ethanol concentration of approximately $50 \%(\mathrm{v} / \mathrm{v})$ prior to filtration and subsequent concentration. The concentrate was used as the antimicrobial fraction. The dry weight of the concentrate after heating at $100^{\circ} \mathrm{C}$ for $24 \mathrm{~h}$ was approximately $97 \mathrm{~g} / \mathrm{kg} \cdot$ paprika seeds. The recovery of activity was much higher in the concentrate of the filtrate from the $50 \%$ ethanol aqueous extract than in that from an aqueous extract alone.

The antimicrobial activity toward film-forming yeasts isolated from ume-zuke containing sulfur dioxide, sorbic acid, acetic acid, and thiamine dilauryl sulfate as well as the $50 \%$ ethanol aqueous paprika seed extract (paprika seed extract) was investigated. This is because acetic acid is a common commercial food preservative, and thiamine dilaur$\mathrm{yl}$ sulfate is often used for preserving processed ume products. Furthermore, sulfur dioxide and sorbic acid are also common commercial food preservatives, including ume products.

Thirteen strains from 4 species were isolated from ume fruits just after the addition of salt for preservation and from ume vinegar obtained between 1 and 6 weeks after the salt addition (Onda et al., 1997b). Film formation began 3 weeks after the salt addition. The film attained a width of about 0.5 $\mathrm{cm}$ in 6 weeks. Table 1 shows the MIC (minimum inhibitory concentration) of the paprika seed extract and the four antimicrobial substances toward the film-forming yeasts. The paprika seed extract demonstrated an inhibitory effect toward 5 strains from 4 species of the film-forming yeasts isolated at

Table 1. Minimum inhibitory concentration (MIC) for film-forming yeasts isolated from ume-zuke of paprika seed extract, sulfur dioxide, sorbic acid, thiamine dilauryl sulfate and acetic acid.

\begin{tabular}{|c|c|c|c|c|c|}
\hline \multirow{2}{*}{ Strain } & \multicolumn{5}{|c|}{$\operatorname{MIC}^{a)}(\mu \mathrm{g} / \mathrm{ml}$ ume vinegar medium $)$} \\
\hline & Paprika seed extract & Sulfur dioxide & Sorbic acid & Thiamine dilauryl sulfate & Acetic acid \\
\hline Kloeckera apiculata YITC 203 & 50 & 3.1 & 100 & 50 & 3000 \\
\hline Pichia anomala YITC 201 & 100 & 6.3 & 50 & 50 & 7000 \\
\hline Pichia anomala YITC 256 & 100 & 3.1 & 100 & 50 & 3000 \\
\hline Candida guilliermondii $\quad$ YITC 222 & 100 & 12.5 & 25 & 50 & 3000 \\
\hline Debaryomyces hansenii YITC 214 & 100 & 6.3 & 100 & 10 & 3000 \\
\hline
\end{tabular}

a) Dilution method. 
different times during salt preservation, and inhibited the growth of Kloeckera apiculata 203 at $50 \mu \mathrm{g} / \mathrm{ml}$, and the other yeasts at $100 \mu \mathrm{g} / \mathrm{ml}$. Sulfur dioxide, sorbic acid, thiamine dilauryl sulfate, and acetic acid inhibited the growth of the five film-forming yeasts at a concentration between 3.1 and $12.5 \mu \mathrm{g} / \mathrm{ml}, 25$ and $100 \mu \mathrm{g} / \mathrm{ml}, 10$ and $50 \mu \mathrm{g} / \mathrm{ml}$, and 3000 and $7000 \mu \mathrm{g} / \mathrm{ml}$, respectively. The MIC of sulfur dioxide and thiamine dilauryl sulfate was lower than that of the paprika seed extract, whereas the inhibitory effect of sorbic acid was identical to that of the paprika seed extract on 2 of the 5 yeast strains tested and higher in the other 2 strains. In contrast to these substances, the growth of the yeasts was not inhibited by the 7 organic acids-adipic acid, fumaric acid, succinic acid, lactic acid, gluconic acid, malic acid, and citric acid-or ethanol and glycine, at higher concentrations. Little if any antimicrobial activity against the film-forming yeasts was expected in the case of only the organic acids because the tested yeasts were isolated from ume vinegar with a high concentration of salt (20\%) and low pH (about 2). Furthermore, $P$. anomala and $C$. guilliermondii can assimilate citric acid and malic acid, which are contained in ume vinegar. The MIC of thiamine dilauryl sulfate was between that of sulfur dioxide and sorbic acid. The MIC of thiamine dilauryl sulfate has not been reported.

Effect of initial number of yeast cells, temperature, $p H$, and sodium chloride concentration on antimicrobial activity of paprika seed extract Figure 1 shows the effect of the initial number of $P$. anomala YITC 256 yeast cells (Fig. 1-a), temperature (b), $\mathrm{pH}(\mathrm{c})$, and sodium chloride concentration (d) on the antimicrobial activity of the paprika seed extract. $P$. anomala YITC 256 is one of the most frequently found strains in ume vinegar with a low $\mathrm{pH}$. This strain was present at the time the film formation began, and is an important part of the inhibition of film-forming by ume-zuke (Onda et al., 1997b). The MIC of the paprika seed extract was 25 to 100 $\mu \mathrm{g} / \mathrm{ml}$ when the initial number of yeast cells was $10^{2}$ to $10^{6}$ cells $/ \mathrm{ml}$ in the ume vinegar medium containing $4.4 \% \mathrm{NaCl}$ $(\mathrm{pH} 2.0)$ and the culture was incubated at $25^{\circ} \mathrm{C}$. However, the growth was not inhibited even at an extract concentration of $300 \mu \mathrm{g} / \mathrm{ml}$ when the initial number was $10^{7}$ cells $/ \mathrm{ml}$. The ume vinegar medium with $10^{5}$ yeast cells $/ \mathrm{ml}$ was a clear solution and that with $10^{6}$ cells $/ \mathrm{ml}$ was slightly cloudy $\left(\mathrm{A}_{660}=\right.$ about 0.1$)$, while that with $10^{7} \mathrm{cells} / \mathrm{ml}$ was very cloudy. These results suggest that the effective prevention of film formation can be expected if the paprika seed extract is added before the ume vinegar becomes cloudy.

When the initial solution of $P$. anomala YITC 256 was inoculated into the medium at $10^{5}$ cells $/ \mathrm{ml}$ and incubated at different temperatures, which varied at $5^{\circ} \mathrm{C}$ intervals from 10 to $35^{\circ} \mathrm{C}$, for 10 days, the MIC toward the yeast of the paprika seed extract was markedly lower at the lower incubation temperature (Fig. 1-b).

Similarly, the MIC toward the yeast of the paprika seed extract was lower in an ume vinegar medium with a lower $\mathrm{pH}$ (range: 1.5 to 4.0 ) (Fig. 1-c). This $\mathrm{pH}$ effect is similar to that observed in carboxylic acid-based antimicrobial substances. Pitt (1974) reported that the maximum concentration of sorbic acid that still permits the growth of yeast (Pichia membranaefaciens) is $100 \mu \mathrm{g} / \mathrm{ml}$ at a $\mathrm{pH}$ of 2.5 to $3.0,200$ $\mu \mathrm{g} / \mathrm{ml}$ at $\mathrm{pH} 3.5$, and $300 \mu \mathrm{g} / \mathrm{ml}$ at $\mathrm{pH} 4.0$. Nomoto et al. (1955) reported that the MIC toward the yeast (Saccharomyces cerevisiae) of sorbic acid is $20-100 \mu \mathrm{g} / \mathrm{ml}$ at $\mathrm{pH} 3.8$ and $200-1000 \mu \mathrm{g} / \mathrm{ml}$ at $\mathrm{pH}$ 5.3. Yamamoto et al. (1984) reported that the MIC toward yeasts that are not resistant to the salt of acetic acid is between 3.5 and $4.0 \%$ and 1.3 to $1.4 \%$ toward yeasts resistant to salt. In contrast, the MIC of sorbic acid and acetic acid in the present study was lower. This may be due to differences in the composition and $\mathrm{pH}$ of the media used. In the present study, the proportion of undissociated acetic acid and sorbic acid in the ume vinegar medium was greater than that in the media reported by Pitt (1974) and Yamamoto et al. (1984) for the same concentration of each organic acid because the $\mathrm{pH}$ of the ume vinegar medium was lower than those of the media used by Pitt and Yamamoto et al. The antimicrobial activity of sorbic acid should be similar
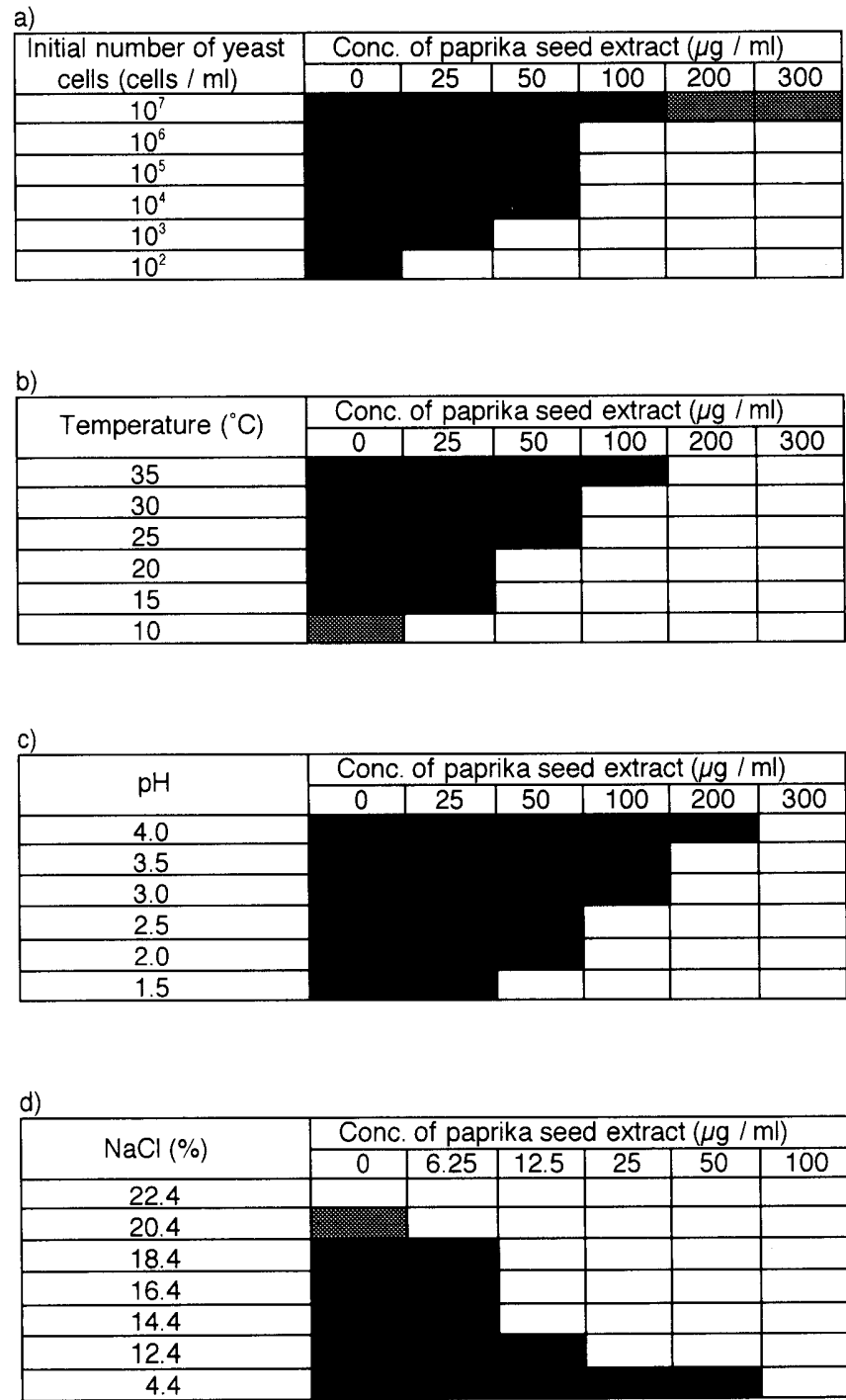

Fig. 1. Effect of initial number of $P$. anomala YITC 256 cells (a), temperature (b), $\mathrm{pH}(\mathrm{c})$, and sodium chloride concentration (d) of the culture medium (ume vinegar) on antimicrobial activity of the yeast. The initial number of yeast cells in (b), (c), and (d) was $10^{5}$. The $\mathrm{pH}$ was adjusted using $1 \mathrm{~N} \mathrm{HCl}$ or $1 \mathrm{~N}$ $\mathrm{NaOH}$. Shading: strong yeast growth; weak yeast growth. (a): Temperature $25^{\circ} \mathrm{C}$, pH 2.0, $\mathrm{NaCl} 4.4 \%$. (b): $\mathrm{pH} \mathrm{2.0.} \mathrm{NaCl} 4.4 \%$. (c): Temperature $25^{\circ} \mathrm{C}, \mathrm{NaCl} 4.4 \%$. (d): Temperature $25^{\circ} \mathrm{C}, \mathrm{pH} 4.4 \%$. 
Table 2. MIC toward film-forming yeasts isolated from ume-zuke for combinations of paprika seed extract (PSE) with each antimicrobial substance.

\begin{tabular}{|c|c|c|c|c|}
\hline \multirow{2}{*}{ Strain } & \multicolumn{4}{|c|}{$\operatorname{MIC}^{a)}(\mu \mathrm{g} / \mathrm{ml}$ ume vinegar medium $)$} \\
\hline & PSE + Sulfur dioxide & PSE + Sorbic acid & PSE + Thiamine dilauryl sulfate & PSE + Acetic acid \\
\hline Kloeckera apiculata YITC 203 & $50+1.6$ & $50+5$ & $50+5$ & $50+1000$ \\
\hline Pichia anomala YITC 201 & $50+3.1^{b)}$ & $50+25^{b)}$ & $50+30$ & $50+1000^{b)}$ \\
\hline Pichia anomala YITC 256 & $50+3.1$ & $50+12.5^{b)}$ & $75+30$ & $25+1000^{b)}$ \\
\hline Candida guilliermondii YITC 222 & $50+3.1^{b)}$ & $50+25$ & $50+2.5^{b)}$ & $50+500$ \\
\hline Debaryomyces hansenii YITC 214 & $50+3.1^{b)}$ & $50+25^{b)}$ & $25+2.5^{c)}$ & $25+1000^{b)}$ \\
\hline
\end{tabular}

${ }^{a)}$ Dilution method.

${ }^{b}$ Cumulative effect.

${ }^{c)}$ Synergistic effect.

at a pH below 3.0 because the $\mathrm{pKa}$ of sorbic acid is 4.75 and the proportion of undissociated sorbic acid is approximately 98\% of the total (Sofos \& Busta, 1981). The MIC of carboxylic acid-based preservatives should be almost the same at a $\mathrm{pH}$ that is comparatively lower than their $\mathrm{pKa}$, because at such a $\mathrm{pH}$, almost all the preservative molecules become undissociated. Although the component of the paprika seed extract that demonstrates antimicrobial activity has not yet been identified, the MIC of this extract decreased with a decrease in the $\mathrm{pH}$ of the medium (range: 1.5 to 4.0 ). Thus, the $\mathrm{pH}$ effect on the antimicrobial activity differs from that of the well-known carboxylic acid-based preservatives. The antimicrobial activity of fatty acid esters is not generally influenced by the $\mathrm{pH}$ of the medium. However, Kato and Shibasaki (1975) reported that the antimicrobial activity of glycerol monolaurate (a fatty acid ester) was much higher than that of lauric acid (fatty acid) and slightly increased with a decrease in $\mathrm{pH}$. The relationship between the antimicrobial activity of the paprika seed extract and the structure of the antimicrobial substance remains unclear and should be examined more closely in the future.

The sodium chloride concentration influenced the film formation of Pichia anomala YITC 256 such that the yeast did not grow in the presence of $22.4 \%$ sodium chloride in the ume vinegar medium. In general, the higher the concentration of sodium chloride, the lower the MIC of the paprika seed extract (Fig. 1-d).

Based on these results, the MIC of the paprika seed extract toward $P$. anomala YITC 256 tends to be lower for a lower initial number of yeast cells, incubation temperature, and $\mathrm{pH}$ of the culture medium, and higher concentration of sodium chloride. The paprika seed extract would thus be maximally effective as a preservative for ume-zuke when employed in an ume processing plant under sterile conditions at a low temperature, using sterilized fruits and an ume vinegar of low $\mathrm{pH}$ in the presence of a high concentration of sodium chloride.

Inhibitory effects of paprika seed extract in combination with other preservatives An antimicrobial synergism or additional effects toward the 5 yeast strains ( $K$. apiculata YITC 203, $P$. anomala YITC 201 and YITC 256, $C$. guilliermondii YITC 222, and D. hansenii YITC 214) were tested using combinations of the paprika seed extract and $\mathrm{SO}_{2}$, sorbic acid, acetic acid, or thiamine dilauryl sulfate. The tests were performed using various concentrations of the paprika seed extract and each preservative. Typical results are shown in Table 2. Compared to the MICs in Table 1, the combination of the paprika seed extract and $\mathrm{SO}_{2}$, sorbic acid, acetic acid, or thiamine dilauryl sulfate tended not to be synergistic but there were a few exceptions. In general, the effects toward the four yeasts, $P$. anomala YITC 201 and YITC 256, C. guilliermondii YITC 222, and D. hansenii YITC 214, were cumulative. The effect was only considered synergistic if the MIC of both preservatives decreased to approximately $1 / 4$ of the MIC of each preservative alone. A decrease to approximately $1 / 2$ was considered to be cumulative. These results are shown in Table 2.

The present study demonstrated that paprika seed extract is highly inhibitory to the growth of film-forming yeasts in ume-zuke and that its inhibitory effect is cumulatively augmented to a significant extent in combination with $\mathrm{SO}_{2}$, thiamine dilauryl sulfate, sorbic acid, or acetic acid. Thus, the addition of the paprika seed extract to ume-zuke appears to provide an effective preservative that enables ume-zuke to be stored for a long period time, thereby enhancing its commercial value.

\section{References}

Kato, N. and Shibasaki, I. (1975). Comparison of antimicrobial activities of fatty acids and their esters. Hakko Kogaku Kaishi, 53, 793-801 (in Japanese)

Nomoto, M., Narahashi, Yn and Niikawa, Y. (1955). Studies on the antimicrobial action of sorbic acid.-The effect of medium $\mathrm{pH}$ on its inhibitory power. J. Agric. Chem. Soc. Jpn., 29, 805-809.

Onda, T., Otoguro, C., Iino, S. and Goto, S. (1997a). Identification and characterization of film-forming yeasts isolated from decomposing salted-processed products. Nippon Shokuhin Kagaku Kogaku Kaishi, 44, 407-431 (in Japanese).

Onda, T., Otoguro, C., Iino, S. and Goto, S. (1997b). Analysis of mechanism of decomposing process contaminated with film-forming yeasts in 'ume-zuke,' salted ume-processed product. Nippon Shokuhin Kagaku Kogaku Kaishi, 44, 463-469 (in Japanese).

Pitt, J.I. (1974). Resistance of some food spoilage yeasts to preservatives. Food Technol. Aust., 26, 238-241.

Sofos, J.N. and Busta, F.F. (1981). Antimicrobial activity of sorbate. J. Food Prot., 44, 614-622.

Yajima, M., Takayanagi, T., Nozaki, T. and Yokotsuka, K. (1996). Inhibitory effect of paprika seed extract on the growth of yeast. Food Sci. Technol. Int., 2, 234-238.

Yajima, M., Nozaki, T., Takayanagi, T. and Yokotsuka, K. (1997). An antimicrobial fraction from the residue obtained by supercritical carbon dioxide extraction of Capsicum spp. for use in food preservation. J. Antibact. Antifung. Agents, 25, 131-137.

Yamamoto, Y., Higashi, K. and Yoshii, H. (1984). Inhibitory activity of acetic acid on yeasts. Nippon Shokuhin Kagaku Kogaku Kaishi, 31, 772-776 (in Japanese) 